\title{
THE STRATEGIC IMPORTANCE OF PURCHAISING DECISIONS IN ACHIEVING COMPETITIVE ADVANTAGE. A PRACTICAL APPROACH FROM THE FUZZY LOGIC PERSPECTIVE REGARDING THE MULTICRITERIA SELECTION OF SUPPLIERS
}

\author{
Adriana Ioana FILIP (Croitoru $)^{1}$ \\ Lucian SIRB ${ }^{2}$ \\ Alin MOLCUT \\ Monica Ioana TOADER ${ }^{4}$ \\ Diana Nicoleta GEORGESCU ${ }^{5}$
}

\begin{abstract}
Starting from Michael Porter's diagnosis regarding the dynamics of the competitive environment based on five forces and from the perspective of the value chain analysis in achieving the competitive advantage on a cutting edge market, this article proposes an in-depth analysis in the topic of purchasing decisions within economic organizations, whose processes need to be approached strategically in order for organizations to develop and evolve properly. Managing in a proper way the relation with the suppliers of goods, raw materials, and services will determine the costs to decrease and thus the revenues and implicitly the profit will grow, placing the entity on a good track in fighting with competition and bringing benefits for all its stakeholders. Moreover, taking into account that the environment in which organizations operate is often surrounded by uncertainty, the decisional process, especially the strategic one, is characterized by ambiguity, doubled also by the subjectivity of the human factor in decisional reasoning. In this context, choosing the right supplier according to specific selection criteria represents the most important decision of the purchasing function. Sometimes, it requests the implementation of qualitative mathematical methods such fuzzy logic, which is a powerful tool that can efficiently shape the ambiguity within decision-making process and support the organization long-term strategy and competitive market positioning.
\end{abstract}

Keywords: purchasing decisions, strategy, competitive advantage, fuzzy logic

JEL codes: D21, D81, L21

\section{Introduction}

The reason for starting any company is related to the fact that it generates revenues and profit for shareholders, which of course arise from the value created for the customers within a specific market. Irrespective of the activity field and products (goods or services), the main purpose of any company is to achieve competitive advantage on the market by creating added value and by differentiating itself from others competitors through its output and reduction of costs. For creating added value, Michael Porter (1985) introduced the term "value chain analysis", which represents a collection of activities performed by a company or enterprise in order to bring value for its clients. Porter's approach is primarily focusing on company systems and activities, its main purpose is meeting customers' requirements and needs properly and efficiently. In Porter's analysis, he

\footnotetext{
1 "Valahia" University of Targoviste

2 "1 December 1918" University of Alba Iulia

3 "Polytechnic" University of Timisoara

4 “1 December 1918" University of Alba Iulia

5 "Valahia" University of Targoviste
}

DOI: 10.29302/oeconomica.2019.21.1.1 
classifies value chain analysis activities into primary and support ones, as shown in the figure below, which fit together and are conducing to profit margin achievement.

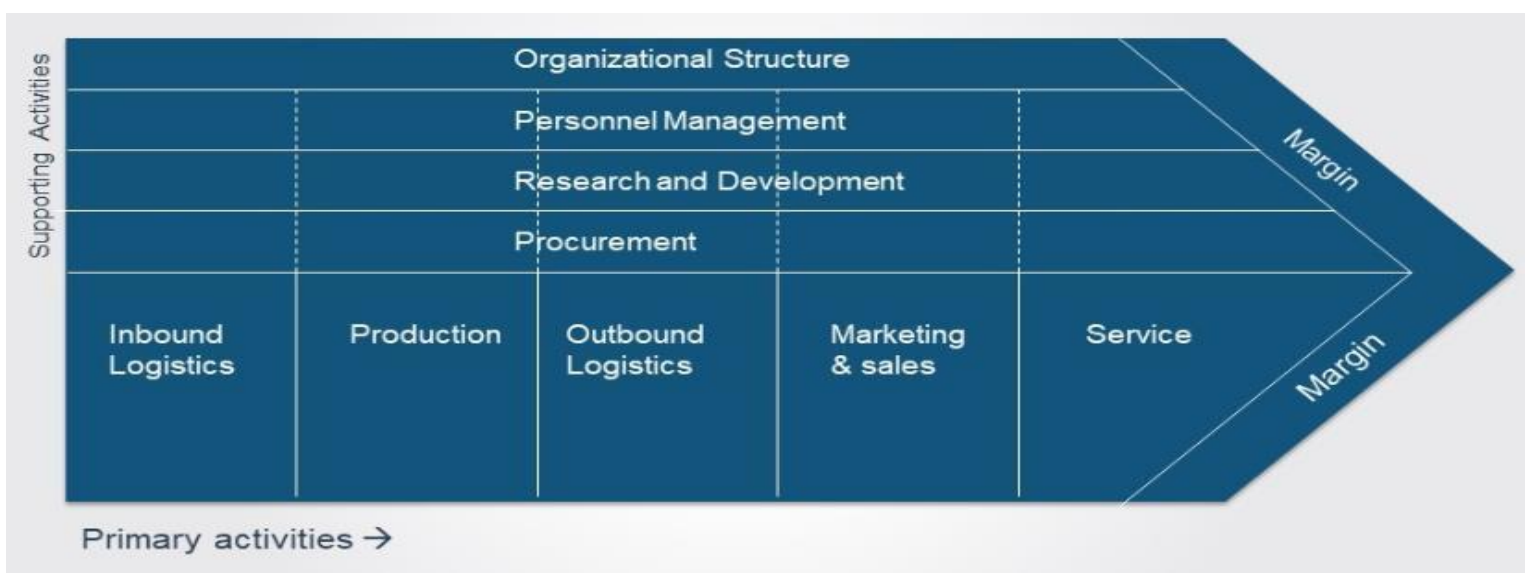

Figure 1. Value chain analysis

Source: Adjustment after Porter (1985)[7].

In other words, from the systemic point of view, this approach describes the organization as a system that converts inputs into outputs via transformation processes. Namely, it involves the acquisition and consumption of resources (i.e., physical, financial, infrastructural, human). The connection of these activities within a systematic approach must drive the organization to satisfy stakeholders' needs and expectations, especially the ones of shareholders, namely to reduce costs, increase sales and revenues.

As it can be noticed, some of the most important activities that secure organizations' profitability are related to purchasing activities, logistics and supply chain management. Effective supply chain management (SCM) has become a potentially valuable way of securing competitive advantage and improving organizational performance since competition is no longer between organizations, but among supply chains (Li et al., 2006). Carr (2002) states that strategic purchasing function can benefit organizations to develop competitive advantage in the following ways: 1) decreasing product/service input costs; 2) Choosing the right suppliers, according to corporate goals of the organization; 3) establishing close relationship with suppliers in order to improve the quality of purchased materials and delivery conditions.

Remaining on the same track of analyzing aspects from a strategic point of view, one can focus on the approach from Porter (2008) regarding the forces that shape strategies. Among these forces, an important part is played by the bargaining power of suppliers and the purchasing function emerging from such interaction. Thus, purchasing plays an important role in achieving corporate strategic success through its main functions: supplier selection and developing a customer-supplier relationship, thus contributing to shape the firm's long-term strategy in obtaining competitive advantage. Managing these aspects in an efficient way can bring significant benefits to organizations, it can eliminate uncertainties and pave the way on which they evolve on the market.

\section{An overview of the purchasing function within supply chain management}

The purchasing function of an enterprise must be viewed as a strategic indispensable tool in achieving competitive advantage on the market, therefore playing an important role in the supply chain management framework. Mainly, its important function is to obtain materials or services of 
the right quality at the right time, in the right quantity, from the right source or supplier, in the right place and at the right price. Because of its role in costs saving, quality improvements and building good relationships with suppliers, purchasing can be viewed as the most important strategic leverage of the supply chain management framework in securing competitive advantage.

The reason for which we state that purchasing function has a strategically role in increasing organization profitability is that most expenditures and costs of an organization (mainly manufacturing companies) are intended for the acquisition of raw materials and semi-finished products from suppliers. Chen et al. (2009) state that "the cost of raw material supply has occupied 60 to 80 percent of sales income in process industry as surveyed". Taking the most suitable decisions in this regard and negotiating properly with suppliers can decrease costs and, automatically, increase the margin profit of an organization. Furthermore, selecting the most suitable supplier represents the main goal of the purchasing system (Figure 2), aspect tackled in the next section, from the fuzzy logic perspective.

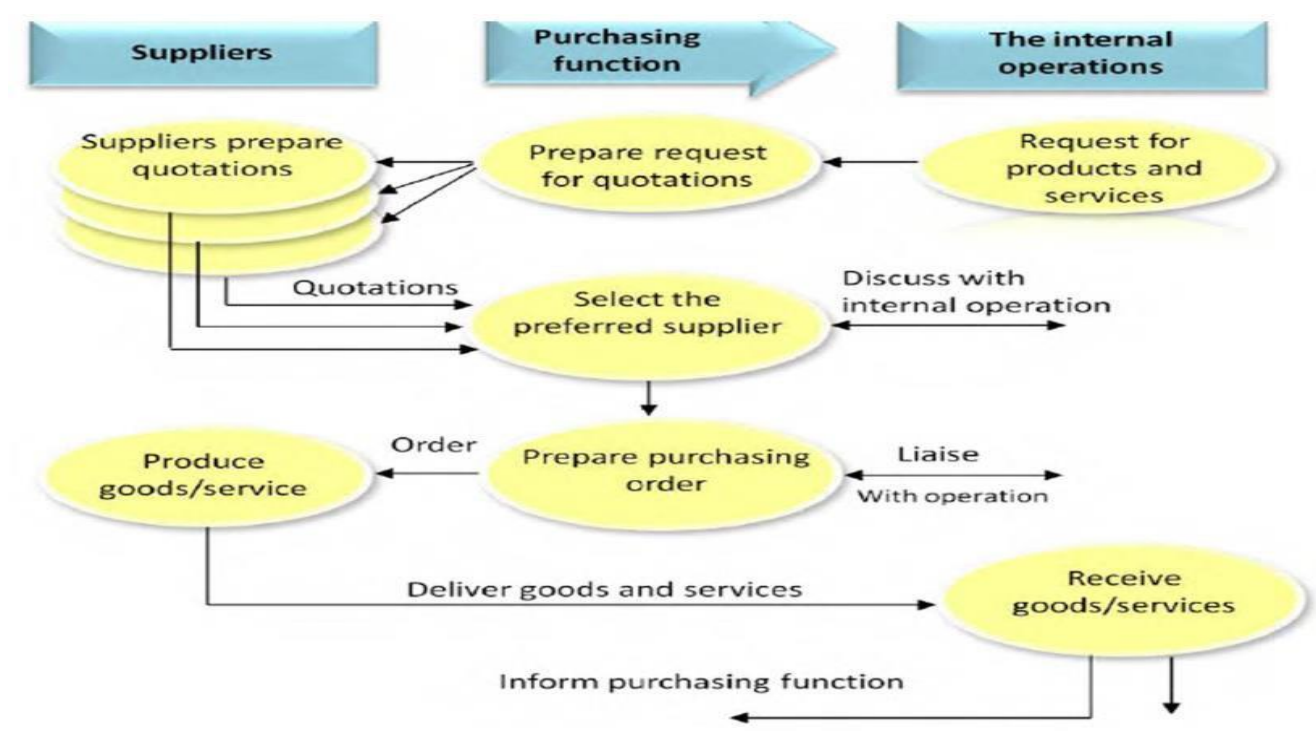

Figure 2 - An overview over the purchasing function within supply chain management (the picture is from own source)

Basically, the purchasing function is the link between the company's internal operations and the supply sourcing, ensuring that the right suppliers are found and are engaged in delivering the required materials, components or services in order to facilitate customer requirements about the final finished products or services in conditions of quality, efficiency and performance. These represent the visible part of the purchasing function, because beyond this companies must take strategic decisions, such as: manufacturing or buying; negotiating; offering discounts and benefits; developing supplier chains and research collaborations.

The concept of supply chain management has been tackled from different points of view in various bodies of literature such as purchasing and supply management, logistics and transportation, operations management, marketing, organizational theory and management information systems (Li et al., 2006). From a theoretical and practical point of view, the purchasing aspect is continuously developing. Carr (2002) states that the strategic role of purchasing has continuously been in the center of attention both in academic journals and popular press since mid-80s. 
The specialty literature reports a lot of studies that investigate this topic. For example, Seyedhosseini et al. (2012) assess strategies in order to minimize total costs of supply chain, while Chen et al. (2009) propose an improved genetic algorithm to decide the optimal ordered quantities of each supplier based on method of Gauss Mapping, improved adaptive penalty function and chaotic migration. Rizza (2010) investigates raw materials sourcing challenges of 31 companies across five industries, providing course-correction strategies and tactics that favor wining results. Gao and Tang (2003) use a multi-objective model for purchasing bulk raw materials for a largescale integrated steel plant. At the same time, Li et al. (2006) also have an interesting study regarding the impact of supply chain management practices on competitive advantage and organizational performance. Namely, they conceptualize and develop five dimensions of supply chain management practices like strategic supplier partnership or customer relationship and test the relationship between these practices, competitive advantage and organizational performance. Moreover, Pal et al. (2013) analyze the supplier selection criteria and methods in supply chains from different points of view, while Sirb (2012) debates issues regarding the management of suppliers' selection of dangerous substances within the mining industry using fuzzy logic. Basically, as Sanchez-Rodriguez (2009) states, there are numerous authors that define purchasing as the function of obtaining competitive advantage especially by properly selecting suppliers using multicriterial conditions.

A qualitative approach regarding the main goal of strategic purchasing decisions from the fuzzy logic perspective within the automotive industry

As mentioned in the abovementioned paragraphs, one of the strategic steps of the purchasing function is to seek, identify, negotiate and select the right supplier for the right raw material or component needed in manufacturing. This is relevant especially when talking about strategic components or bottleneck components. The quality provided by suppliers and the proper selection of suppliers will have a direct impact on the supply chain and company competitiveness on the market. Thus, the selection of suppliers that deliver high quantities of raw materials, which also have a high quality, is considered to be a strategic decision (Seyedhosseini, 2012). In this context, the decisions to be taken are often multicriterial ones, are surrounded by uncertainty and by the subjectivity of human factor reasoning. Consequently, in some cases, these decisions need to be modelled using a qualitative tool as fuzzy logic. The methods of fuzzy multicriteria decisionmaking have been developed due to the imprecision in assessing the relative importance of selection criteria and due to the subjective estimating of the performance of decisional alternatives with respect to these criteria. The imprecision may derive from several aspects: unquantifiable information, incomplete information, information impossible to obtain, ignorance. To overcome this obstacle, fuzzy sets theory was developed to improve the reliability of decision-making process under uncertainty (Bellman and Zadeh, 1970).

Normally, the process of selecting suppliers involves the following steps, but it does not mean that these are universal and comprehensive: 1) establishing selection criteria; 2) initial contact; 3) request for price quotation; 4) supplier visit, audits, assessment or surveys; 5) initial test before contracting and effectively signing the contract. Within this process, some criteria are essential for a suitable selection and most of them cannot be evaluated only in a quantitative manner, but request another approach based on qualitative values. This approach can be modeled by a flexible and efficient methodology based on fuzzy logic, which is able to consistently model ambiguity and uncertainty within different decisional situations also doubled by the subjectivity of human factors involved in this selection process, who express themselves by using linguistic variables.

The fuzzy methodology we propose in this article was implemented on a hypothetical case study related to the proper selection of suppliers for a company from the automotive industry. In this practical example, evaluations have been conducted using linguistic variables converted 
afterwards in triangular fuzzy numbers. For the flexibility of results due to different opinions of decisions makers, we used a software tool designed in Java programming language for providing accurate and reliable results. The steps of the methodology are described below, as follows:

1) The definition of triangular fuzzy numbers through the fuzzification process related to the evaluation of the importance weight of criteria

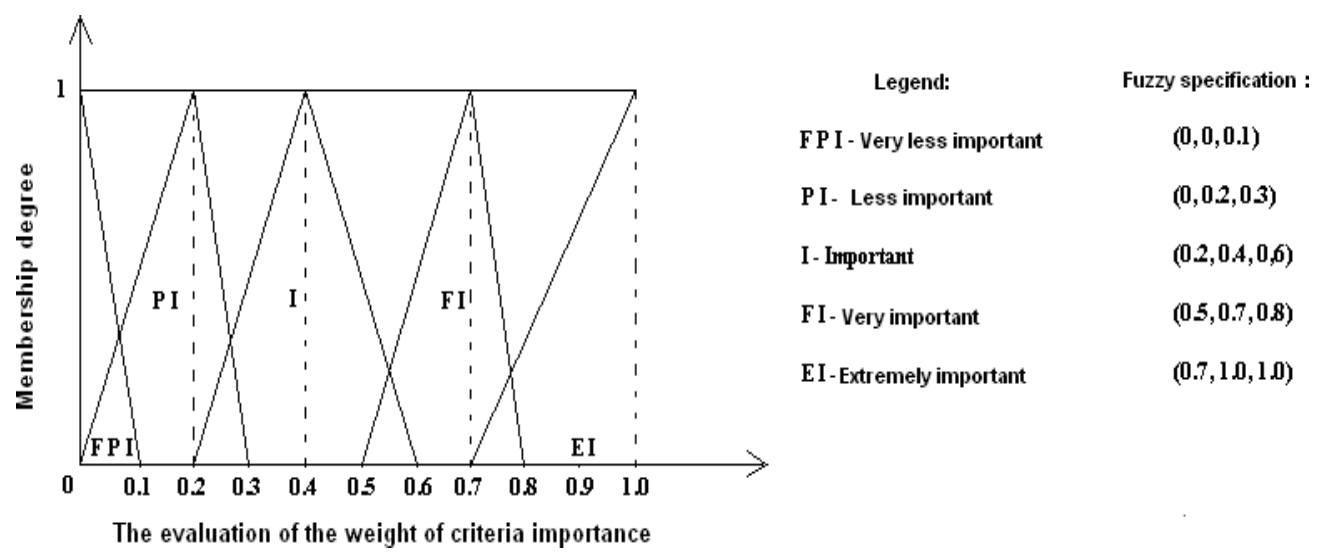

Figure 3 - Fuzzy evaluations regarding the importance weight of criteria (the picture is from own source)

Because we used a special software to efficiently model fuzzy numbers describing the evaluations of importance weight of criteria and the results within operations, for which linguistic evaluations were reported in Romanian, these evaluations from the figure above are equivalent with the below specifications, captured otherwise in the print screen of the fuzzy software:

FPI - "Foarte putin important"

PI - "Putin important"

I - "Important"

FI - "Foarte important"

EI - "Extrem de important"

The linguistic evaluations of the selection criteria are transposed within a matrix with one column and $\mathrm{n}$ lines, noted with $\mathrm{i}$, thus:

$$
I=\left(\begin{array}{ccc}
\text { weight of importance } & \rightarrow & \text { criterion } 1 \\
\text { weight of importance } & \rightarrow & \text { criterion } 2 \\
\vdots & \vdots & \vdots \\
\text { weight of importance } & \rightarrow & \text { criterion } n
\end{array}\right) \text {, where } i=1, \ldots, n \text {. }
$$

The criteria and their related linguistic evaluations regarding the importance weight in our hypothetical example are described below in the printscreen of the software tool. 


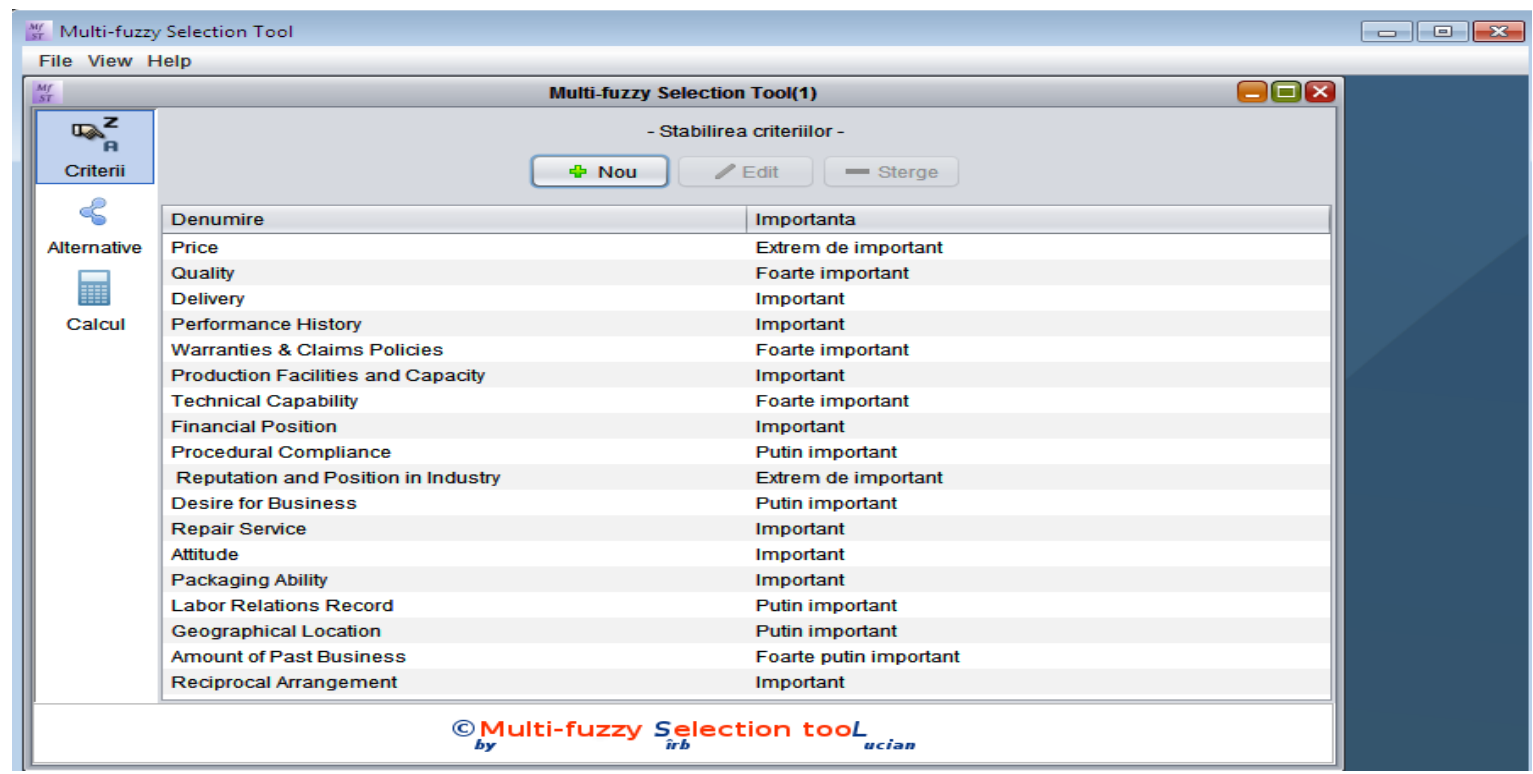

Figure 4 - The software printscreen regarding the evaluation of the importance weight of selection criteria

(the picture is from own source)

2) The definition of the triangular fuzzy numbers through the fuzzification process related to the evaluation of suppliers' performance concerning each selection criterion

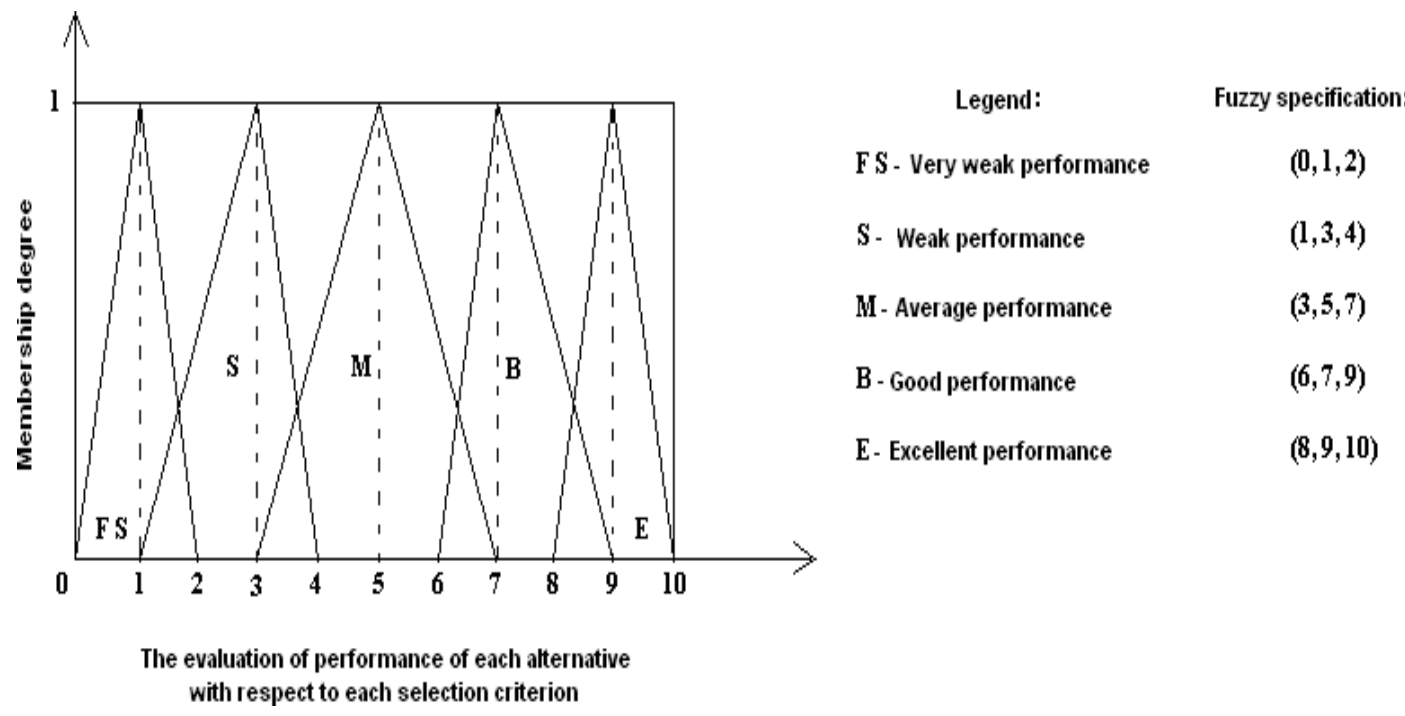

Figure 5 - Fuzzy evaluations regarding the performance of suppliers with respect to each selection criterion

(the picture is from own source)

Since we used a special software in order to efficiently model the fuzzy numbers describing evaluations of suppliers' performance with respect to each selection criterion and their results 
(employing the Romanian language), the evaluations from Figure 5 are equivalent with the below specifications, included in the print screens of this mentioned fuzzy software:

FS - "Performanta foarte slaba"

$\mathrm{S}$ - "Performanta slaba"

M - "Performanta medie"

B - "Performanta buna"

E - "Performanta excelenta"

The linguistic evaluations of the performance of potential suppliers from our hypothetical example with respect to each selection criteria will be transposed in a matrix with $m$ rows and $n$ columns $\left(m^{*} n\right)$, noted with $\mathrm{P}$, thus:

$$
P=\left(\begin{array}{cccc}
P_{11} & P_{12} & \ldots & P_{1 n} \\
P_{21} & P_{22} & \ldots & P_{2 n} \\
\vdots & \vdots & \vdots & \vdots \\
P_{m 1} & P_{m 2} & \ldots & P_{m n}
\end{array}\right) \text {, where } i=1, \ldots, n \text { and } j=1, \ldots, m
$$

The linguistic evaluations of the performance of the four suppliers from our hypothetical example with respect to each selection criteria are described in the following printscreens of the software tool used in our analyses.
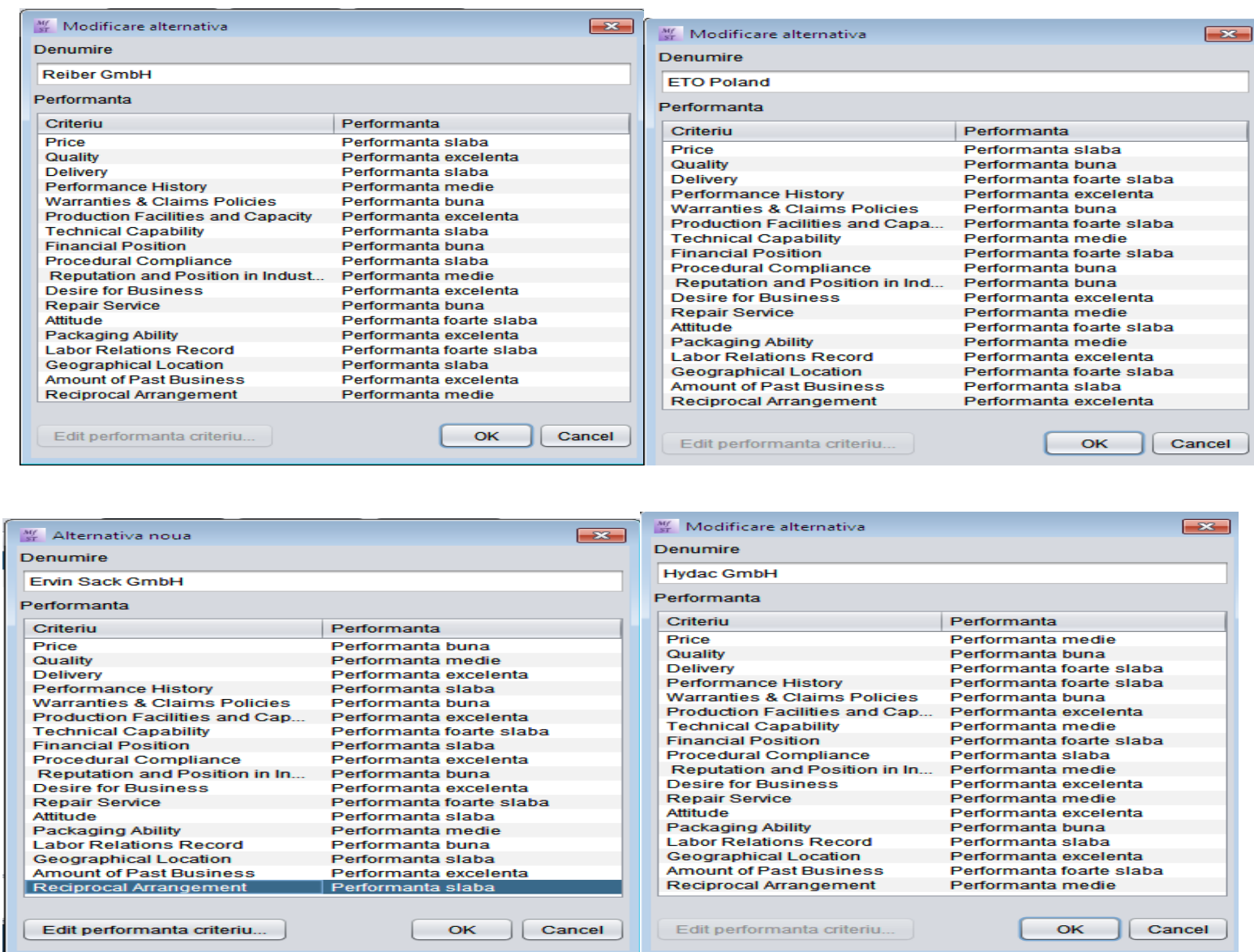

Figure 6 - The software interfaces regarding the evaluation of the performance of each of the four suppliers with respect to selection criteria

(the picture is from own source)

3) Multiplying matrices $P$ and I will generate the solution matrix denoted with $S$, which 
contains on each line the fuzzy score for each potential supplier.

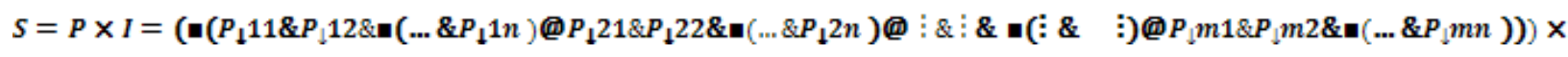

In our hypothetical example, the related print-screen of the software describes the following results:

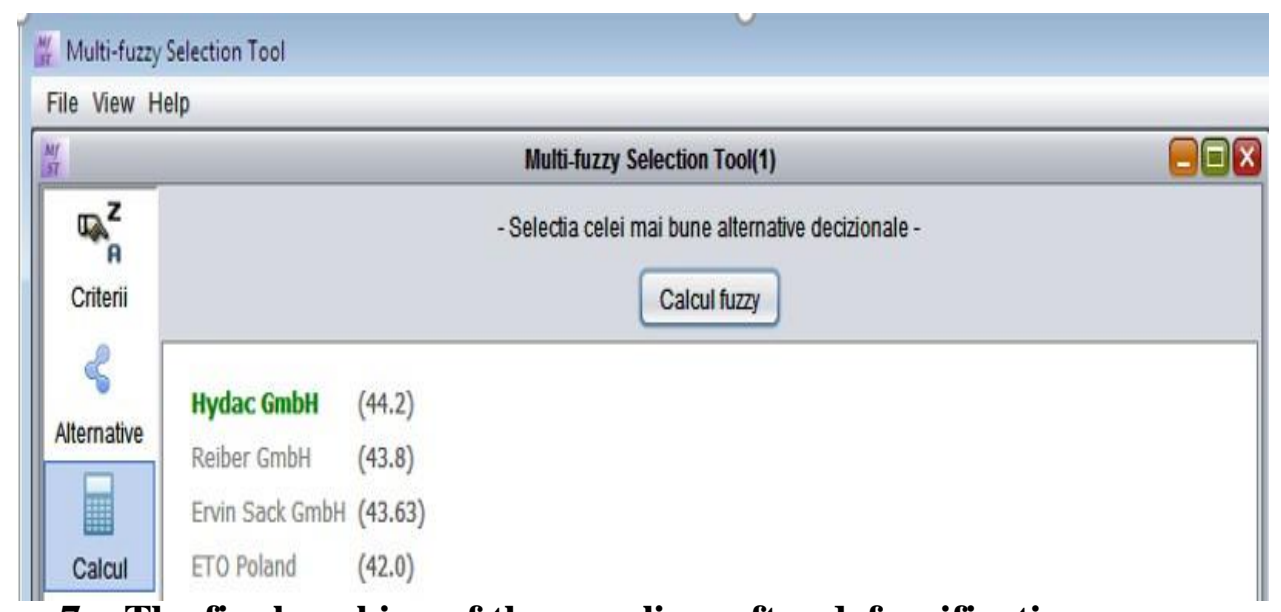

Figure 7 - The final ranking of the suppliers after defuzzification process

(the picture is from own source)

Results are provided by each row of the matrix $S$, after the process of defuzzification of the fuzzy scores represented by triangular fuzzy numbers, through the centroid method, thus:

$$
D\left(s_{j}\right)=\frac{s_{j}^{1}+s_{j}^{2}+s_{j}^{3}}{3}, \text { where } j=1, \ldots, m \text {. }
$$


As it can be noticed, Hydac Gmbh has proved to be the most suitable supplier to be selected from the automotive industry, given the linguistic evaluations in the context of the implementation of the proposed fuzzy methodology.

\section{Conclusions and future directions}

The main conclusion of this paper is that supplier selection process can be considered to be the main goal of purchasing management in an organization. Of course, in order to succeed on the market, this aspect must be doubled by close relationships with selected suppliers for obtaining the necessary performance, capability improvements and research innovations in long term. Thus, the strategic importance of purchasing decisions for achieving competitive advantage can be summarized into two aspects: differentiation/quality; cost reductions.

The fuzzy methodology from this article used for shaping uncertainty and ambiguity within decisional environment, or subjectivity of human factor reasoning often expressed through linguistic variables, can be considered a multidisciplinary one, involving aspects from mathematics, economics, psychology or informatics.

For future research directions, this fuzzy methodology could be applied in others areas within decision-making process, either strategical, tactical or operational, proving its level of efficiency and reliability in similar circumstances.

\section{References}

1. Bellman, R. E., Zadeh, L. A., 1970. Decision-making in a fuzzy environment, Management Science, 17, pp. 141-164.

2. Carr A. S., 2002. The impact of purchasing and supplier involvement on strategic purchasing and its impact on firm's performance, International Journal of Operations and Production Management, 22(9), pp. 1032-1053.

3. Chen, X.-F., Cen, L.-H., Cen, Y.G., 2009. A raw material purchasing decision-making model of order allocation with multiple suppliers and its optimization, The $1^{\text {st }}$ International Conference on Information Science and Engineering, accessed on-line at https://ieeexplore.ieee.org/stamp/stamp.jsp?tp=\&arnumber=5454912 on 15.10.2018.

4. Gao, Z., Tang, L., 2003. A multi-objective model for purchasing of bulk raw materials of a largescale integrated steel plant, International Journal of Production Economics, 83, pp. 325-334.

5. Li, S., Ragu-Nathan, B., Ragu-Nathan, T. S., Subba Rao, S., 2006. The impact of supply management practices on competitive advantage and organizational performance, Omega- The International Journal of Management Science, pp. 107-124.

6. Pal, O., Gupta, A. K., Garg, R. K., 2013. Supplier selection criteria and methods in supply chains: A review, International Journal of Economics and Management Engineering, 7(10), pp. 2667-2673.

7. Porter, M. E., 1985. Competitive Advantage. New York, The Free Press.

8. Porter, M. E., 2008. The five competitive forces that shape strategy, Harvard Business Review, pp. $1-18$.

9. Rizza, M. N., 2010. Raw material sourcing strategies are critical to revenue and profit margins, AMR Research Supply Management, pp. 1-6.

10. Sanchez-Rodriguez, C., 2009. Effect of strategic purchasing on supplier development and performance: a structural model. Journal of Business \& Industrial Marketing, 24(3), pp. 161-172.

11. Sirb, L., 2012. The management of suppliers' selection of dangerous substances from mining industry using fuzzy logic, Management: New Coordinates and Challenges, Supplement no. 2/2012, pp. 335-345.

12. Seyedhosseini, S. M., Mohammadipour F., Ashtiani M. G., 2012. Make or buy strategy decision making in supply quality chain, International Journal of Industrial Engineering (3), pp. 413-422.

13. Zadeh, L. A., 1965. Fuzzy sets, Information and Control, 8, pp. 338-357.

14. Zadeh, L. A., 1999. Some reflections on the anniversary of Fuzzy Sets and Systems, Fuzzy Sets and Systems, 100, pp. 1-3. 